\title{
Deep brain stimulation for movement disorders
}

\author{
Gilberto Pizzolato ${ }^{1}$ and Tomasz Mandat ${ }^{2,3}$ * \\ ' Neurology Clinic, Department of Medical Sciences, University of Trieste, Trieste, Italy \\ ${ }^{2}$ Department of Neurosurgery, Maria Sklodowska-Curie Memorial Oncology Center-Institute, Warszawa, Poland \\ ${ }^{3}$ Department of Neurosurgery, Institute of Psychiatry and Neurology, Warszawa, Poland
}

Edited by:

Chiara Saviane, Scuola Internazionale Superiore di Studi Avanzati, Italy

Reviewed by:

Romulo Fuentes Flores, Edmond and Lily Safra International Institute of

Neuroscience of Natal, Brazil

Carlo Colosimo, Sapienza University

of Rome, Italy

Lars Wojtecki, University Duesseldorf, Germany

*Correspondence:

Tomasz Mandat, Klinika Nowotworów Układu Nerwowego, Centrum

Onkologii - Instytut, ul. Roentgena 5,

02-781 Warszawa, Poland.

e-mail: tomaszmandat@yahoo.com
Stereotactic technique and the introduction of deep brain stimulation (DBS) can be considered two milestones in the field of surgical neuromodulation. At present the role of DBS in the treatment of clinically and epidemiologically relevant movement disorders is widely accepted and DBS procedures are performed in many clinical centers worldwide. Here we review the current state of the art of DBS treatment for the most common movement disorders: Parkinson's disease, essential tremor, and dystonia. In this review, we give a brief description of the candidate patient selection criteria, the different anatomical targets for each of these condition, and the expected outcomes as well as possible side effects.

Keywords: DBS, movement disorders, Parkinson's disease, dystonia, essential tremor

\section{INTRODUCTION}

Movement disorders encompass a number of neurological diseases affecting the ability to control movement. Movement is in command of several interacting brain structures, including the motor cortex, the cerebellum, and the basal ganglia (BG). The BG comprises a group of interconnected deep brain nuclei [caudate and putamen (C-P), Globus pallidus (GP), substantia nigra (SN), subthalamic nucleus (STN)] that, through their connections with the thalamus and the cortex, primarily influence the involuntary components of the movement and muscle tone. Disruption of this complex circuitry within the BG causes the most frequent movement disorders, such as Parkinson's disease (PD), essential tremor (ET), and dystonia (Alexander et al., 1990). The treatment of these disorders with the deep brain stimulation (DBS) technique is the topic of the present review, which describes the current clinical use and approval of DBS indications.

Already in the 1950s, some early studies evaluated the possible therapeutic benefits of chronic stimulation of the subcortical structure in psychotic patients (Hariz et al., 2010). Nevertheless, modern DBS was first clinically used in the treatment of movement disorders. Several reviews provide a comprehensive account of the symptoms/syndromes that might be the target of this treatment, its clinical efficacy, as well as its possible complications and side effects (Skidmore et al., 2006; Wichmann and Delong, 2006; Collins et al., 2010). The DBS surgical treatment of movement disorders has its foundations in two seminal papers by the "Grenoble Group" of Benabid et al. (1987) describing the combined (thalamotomy and stimulation) stereotactic surgery of the ventral intermediate (VIM) nucleus of the thalamus and, in 1993, DBS of the STN for PD patients (Pollak et al., 1993). Modern DBS followed ablative stereotaxy that was performed for most of the twentieth century for medically refractory severe movement disorders, mostly PD and ET, with selective destruction of parts of the GP or of the thalamus (Schwalb and Hamani, 2008). Although the procedure was largely effective in relieving the symptoms, it was irreversible, and in some cases side effects were actually encountered. As a result, in the 1970s, following the advent of the highly effective levodopa treatment for PD, ablative surgery was largely abandoned. However, after the initial enthusiasm for the medical treatment of PD, it was apparent that long-term levodopa therapy had significant drug-induced complications (the so-called "long-term levodopa syndrome") mainly consisting in involuntary movements (dyskinesias) and motor fluctuations, which could have a severe disabling effect in a significant percentage of levodopa-treated PD patients. In addition, among the classic symptomatologic triad of PD bradykinesia, rigidity, and resting tremor - this latter symptom is always less responsive to levodopa treatment (Fishman, 2008). Therefore, many clinical centers took advantage of the fact that DBS technology is less invasive than stereotactic surgery, and is also reversible and adjustable, more suitable for an increasing number of medically treated PD patients with disabling dyskinesias/motor fluctuations and/or medically refractory tremor (Collins et al., 2010).

The DBS technique uses continuous high-frequency stimulation of specific brain regions through chronically implanted electrodes, connected to a pulse generator, similar to a cardiac pacemaker, that is telemetrically programmable. Electrodes are implanted into the target brain area by using a stereotactic surgical procedure with electrophysiological recordings. Clinically, the effects of DBS mimic those produced by lesioning the target structure (Schwalb and Hamani, 2008). However - at the cellular or pathway level - the actions of high-frequency DBS that mediate its clinical efficacy are not fully understood. Indeed, recent evidence suggests that DBS has more complex mechanisms of action than 
the pure functional inactivation of the target region. For instance, high-frequency stimulation of the most used target structures for DBS in PD and ET, i.e., the STN and the internal part of the GP (GPi), not only produces both inhibitory and excitatory effects on local neurons, but has also a modulatory influence on the afferent inputs to the target nucleus and on the efferent outputs (McIntyre et al., 2004). In any case, the ultimate effect of modulating the network activity within the BG can be viewed as the takeover on hyperactive elements or structures of the cortico-BG-thalamocortical complex circuit (Gradinaru et al., 2009; Kopell et al., 2009; McIntyre and Hahn, 2010).

\section{PARKINSON'S DISEASE}

Parkinson's disease is the second most common neurodegenerative disease. Its complex multifactorial etiology might comprise, from recent genetic and epidemiological studies, genetic susceptibility factors, and environmental risk factors. PD is a progressive disease with age-dependent increasing prevalence (from 1 to $3 \%$ in the population aged over 65 years; Wirdefeldt et al., 2011). Loss of $\mathrm{SN}$ pars compacta $(\mathrm{SNc})$ dopaminergic neurons projecting to the $\mathrm{C}-\mathrm{P}$ is considered the neuropathologic hallmark of PD. The consequent reduced dopaminergic input is considered the cause of the motor manifestations of the disease (bradykinesia, rigidity, resting tremor, and postural instability) and the reason for the remarkable clinical success of dopamine replacement therapy. However, it has become increasingly apparent that the neuropathological changes of PD (mostly alpha-synuclein pathology) extend far beyond the nigro-striatal system, affecting also the olfactory bulbs, and the autonomic nervous system, many structures of the lower brainstem, the limbic system, as well as the mesocortical and neocortical regions. Most of the extra-nigral pathological alterations are considered responsible of the non-motor symptoms of the disease, such as hyposmia, autonomic dysfunctions, sleep disorders, depression, and cognitive impairments (Braak et al., 2003).

Nevertheless, with regard to DBS treatment in $\mathrm{PD}$, the main focus is on the progressive degeneration of the nigro-striatal dopaminergic projections and the appearance of disabling side effects, i.e., motor fluctuations and dyskinesias, in a large percentage of PD patients on long-term dopaminergic therapy (Schrag and Quinn, 2000). Because such complications are often poorly managed by oral therapy, it is estimated that more than $10 \%$ of PD patients could benefit from DBS treatment. The selection of candidate patients for DBS has strict inclusion/exclusion criteria. The best candidates are PD patients with severe motor symptoms in the off-medication condition that continues to indicate a substantial benefit from levodopa therapy, despite the disabling drug-induced motor complications. Main exclusion criteria are the presence of symptoms suggesting an atypical parkinsonian syndrome that usually does not respond to levodopa therapy, or the presence of neuropsychiatric (depression) or cognitive alterations (Bronstein et al., 2011).

There are four possible target sites for the placement of the stimulating electrodes: although stimulation of the VIM thalamic nucleus has a clear effect on tremor, DBS of the STN, or GPi has a broader influence on all parkinsonian symptoms and represents, nowadays, the treatment of choice in most PD patients. A more recent, still experimental, target is the pedunculopontine nucleus (PPN) that may be appropriate for patients with gait freezing (Stefani et al., 2007; Wilcox et al., 2011). Because most patients undergoing the DBS procedure have bilateral symptoms, both right and left STN or GPi are usually implanted for maximal benefit. Any parkinsonian symptom that can improve with levodopa can also improve with DBS. Three recent randomized controlled studies in patients with PD reported that STN DBS plus best medical therapy was more effective than best medical therapy alone in improving motor function and quality of life, but was also associated with an increased risk of serious adverse events (Deuschl et al., 2006; Weaver et al., 2009; Williams et al., 2010). After neurostimulation, the clinical response is more stable during the day, with significant lessening of the "off" periods that are so frequent and disabling in PD patients. Furthermore, DBS reduces levodopa-induced dyskinesias. In the case of STN DBS, this effect could be mostly ascribed to the reduction in medication dose, possible when the stimulation is active. GPi stimulation patients experience a reduction in dyskinesias without any levodopa dose reduction (Weaver et al., 2009; Follett et al., 2010). In addition, reduction of dopaminergic therapy after STN DBS may help in reducing some psychiatric symptoms, like visual hallucinations and impulse control abnormalities, which are frequent behavioral complications in the treatment with dopamine agonists (Lulé et al., 2012).

Complications related to surgery are primarily intracerebral hemorrhage (less than $2 \%$ in most centers) and infection (in about $4 \%$ of the cases; Kleiner-Fisman et al., 2006). STN DBS can worsen speech and gait in some patients, requiring an adjustment of stimulation parameters. A recent study reported that depression worsened with STN DBS but was improved with GPi DBS (Follett et al., 2010). There are several reports that describe neuropsychiatric symptoms following STN DBS in PD patients. However, such symptoms were generally transient and mild if managed appropriately (Volkmann et al., 2010). With these possible complications in mind, we can say that DBS offers important symptomatic benefits in cognitively intact PD patients with moderate disability who still maintain a therapeutic response to levodopa. Mediumand long-term studies have provided evidence that stimulationinduced motor improvement was still evident at 5-8 years' followup (Fasano et al., 2010; Moro et al., 2010). However, DBS does not modify the progression of the underlying PD pathology, so, after years, patients can still develop disabling levodopa-resistant symptoms, like gait disturbances and cognitive impairment.

\section{ESSENTIAL TREMOR}

Essential tremor is one of the most common movement disorders with prevalence that varies depending on age, raising up to $5 \%$ in the population over 60 . The typical postural and action tremor is most often located in the upper limbs; less frequently it affects the head, the tongue, and the lower limbs. Even though the quality of life is impaired by tremor in more than $70 \%$ of patients, only $10 \%$ are medically treated. In addition, only $50 \%$ of treated patients show a good response to therapy (Lyons et al., 2003). In the middle of the twentieth century the ventrolateral thalamus became the main surgical target for parkinsonian and various other types of tremor, including ET. After the introduction, in the early 60s, of micro recording during stereotactic surgery, it became apparent 
that small lesions of the VIM could suppress tremor. Afterward, unilateral stereotactic VIM lesioning was a frequent procedure in many clinical centers worldwide and resulted in a permanent significant contralateral improvement of the most common types of tremor. However, the very satisfactory results in controlling ET and other types of tremors (significant reduction of limb tremor in $80-90 \%$ of patients with ET) obtained thanks to the thalamotomy, were accompanied by a relatively high complication rate, especially if the procedure was performed bilaterally. In fact, almost $30 \%$ of patients who underwent the ablative procedure bilaterally experienced permanent speech and cognitive deficits. Introduction of DBS of the thalamic VIM nucleus in ET treatment helped to reduce complication rate with remaining high efficacy. Therefore, VIM DBS is viewed as the target therapy for these patients with a debilitating ET. Although the exact etiology and pathophysiology of ET is still unknown, it is believed that high-frequency stimulation of the VIM nucleus may block the abnormal oscillatory activity within the interconnected regions, including the cerebellum and the motor cortex (Dostrovsky and Lozano, 2002).

The main exclusion criteria of DBS treatment for ET include altered cognition and the presence of an untreated or disabling psychiatric illness. Patients with ET are considered good DBS candidate if they were also refractory to an adequate trial of accepted oral medications (Katz et al., 2011). The most frequent stimulationinduced side effects are paresthesias, followed by dysarthria and pain, symptoms that are reversible when the stimulation is turned off. Furthermore, gait/balance may worsen following DBS for medication refractory ET (Hwynn et al., 2011). The high initial efficacy of VIM DBS declines over time (Schuurman et al., 2008). However, most patients experience a good response for several years.

\section{DYSTONIA}

Dystonia is a movement disorder that presents with sustained, uncontrolled, often painful muscle contractions causing repetitive movements and abnormal postures. Depending on the localization, dystonia is divided into focal (affecting a single body region), segmental (two or more adjacent areas), or generalized (involving the legs, or one leg and the trunk, plus at least one other area of the body). Depending on etiology, dystonia might be primary (idiopathic) or secondary to a known structural lesion of the brain, like perinatal hypoxia, infections, stroke, and trauma. Idiopathic dystonia in adults is most commonly a focal/segmental disease, like cervical dystonia (the most common form), blepharospasm, or writer's cramp, whereas in children and young adults the generalized inherited forms are more common. There are multiple forms of inheritable dystonia, with the DYT-1 gene mutation, responsible for early-onset generalized dystonia, as the most frequent form (Albanese et al., 2011). Medical therapy is very effective in a very limited subset of dystonia patients (20-40\%). In addition, doses of drug(s) required for therapy often produce intolerable side effects. Dystonia is still one of the most important indications for botulinum toxin (BT) therapy that selectively blocks the cholinergic innervation of the muscles. BT can be used to treat focal dystonias and also the most relevant target muscles in segmental and generalized dystonias. Combinations of BT therapy with all other treatment options, including DBS, are possible.
Patients with dystonia who might be evaluated for DBS treatment should have symptoms that cause significant disability, despite maximally tolerated medical treatment. The factors that influence the selection of patients with various types of dystonia for treatment with DBS have been recently reviewed by BronteStewart et al. (2011). Patients candidate to surgery should undergo DBS treatment before the onset of orthopedic deformities that may impede functional benefit even if dystonia is ameliorated by DBS. The exact pathophysiological mechanisms of dystonia are not completely understood and the best brain target for DBS in dystonic patients has not been quite identified yet. However, a lot of evidence indicates that the interplay between the BG and cerebellar circuits has a major role. In particular, the GPi has been proven to show an abnormal firing activity in dystonia, and GPi is the usual target of DBS for such patients. On the other hand, previous studies on STN stimulation in dystonia gave contrasting results (Detante et al., 2004; Sun et al., 2007). In a 3-year follow-up study, the beneficial effects of bilateral GPi stimulation in young patients with identified DYT-1 mutation reached 90\% (Coubes et al., 2000). Positive effects of DBS on dystonia scales, quality of life, and pain reduction have been confirmed in different studies also in adults with primary generalized dystonia and in heterogeneous groups comprising patients with secondary or focal disease (Vidailhet et al., 2005; Kupsch et al., 2006; Andrews et al., 2010). Dynamic movements are the first that respond to DBS, whereas improvement of persistent dystonic posture could be observed after months or years (Welter et al., 2010). Because improvement may take months to occur, the evaluation of the efficacy of DBS treatment is more challenging than in patients with PD or ET. Another difference with the DBS system in PD is that the optimal frequency and amplitude stimulation settings needed for DBS in many dystonia patients are higher than for GPi DBS in PD, and much higher than for STN DBS in PD patients.

\section{PERSPECTIVES ON EVOLUTION OF DEEP BRAIN STIMULATION}

Currently, the DBS technique uses electrodes of $1.3 \mathrm{~mm}$ in diameter integrating four contacts of $1.5 \mathrm{~mm}$ length each, connected to an internal pulse generator. Minimizing the hardware dimensions remains one of the goals of DBS development, to allow the implantation of the internal pulse generator in the scalp or within the skull. Minimizing the size of the hardware would also allow implanting multiple electrodes to multiple anatomical targets of the brain more precisely and effectively. Further development of DBS will probably depend on the use of multiple electrodes with "closed-loop" systems that include macro recordings and stimulation. The influence of local monitoring of neurotransmitter activity might impact on the patterns of stimulation, particularly with regard to the interactions between stimulation and medications. Moreover, since the introduction of the DBS technique the lifespan of the battery has increased twice, but programming the stimulation today is performed via telemetry that requires several time consuming visits before the best therapeutic effect can be reached. In the future, development of "closed-loop" DBS systems and neuroimaging modalities might allow the performance of effective and safe programming through remote access, such as the telephone or the Net (Andrews, 2010; Shah et al., 2010). 
The role of DBS for PD, ET, and dystonia is a well-established treatment option, currently approved for use in the United States (DBS for drug refractory primary dystonia received in 2003 the FDA approval as humanitarian use device - HUD), Canada, Europe, and Australia. As the indications for DBS broaden to include other neurological and psychiatric conditions, the number of DBS implants worldwide is expected to grow in the next years. In 2009, treatment with DBS of obsessive compulsive disorder (OCD) was approved by FDA as HUD and received the CE mark approval. In 2010, the CE mark for DBS treatment of Epilepsy refractory to medical treatment was also granted. On-going clinical trials with DBS in the treatment of mood disorders, tremor

\section{REFERENCES}

Albanese, A., Asmus, F., Bhatia, K. P., Elia, A. E., Elibol, B., Filippini, G., Gasser, T., Krauss, J. K., Nardocci, N., Newton, A., and Valls-Solé, J. (2011). EFNS guidelines on diagnosis and treatment of primary dystonias. Eur. J. Neurol. 18, 5-18.

Alexander, G. E., Crutcher, M. D., and DeLong, M. R. (1990). Basal ganglia-thalamocortical circuits: parallel substrates for motor, oculomotor, "prefrontal" and "limbic" functions. Prog. Brain Res. 85, 119-146.

Andrews, C., Aviles-Olmos, I., Hariz, M., and Foltynie, T. (2010). Which patients with dystonia benefit from deep brain stimulation? A metaregression of individual patient outcomes. J. Neurol. Neurosurg. Psychiatr. 81, 1383-1389.

Andrews, R. J. (2010). Neuromodulation advances in the next decade. Ann. N. Y. Acad. Sci. 1199, 212-220.

Benabid, A. L., Pollak, P., Louveau, A., Henry, S., and de Rougemont, J. (1987). Combined (thalamotomy and stimulation) stereotactic surgery of the VIM thalamic nucleus for bilateral Parkinson disease. Appl. Neurophysiol. 50, 344-346.

Braak, H., Del Tredici, K., Rub, U., de Vos, R. A., Jansen Steur, E. N., and Braak, E. (2003). Staging of brain pathology related to sporadic Parkinson's disease. Neurobiol. Aging 24, 197-211.

Bronstein, J. M., Tagliati, M., Alterman, R. L., Lozano, A. M., Volkmann, J., Stefani, A., Horak, F. B., Okun, M. S., Foote, K. D., Krack, P., Pahwa, R., Henderson, J. M., Hariz, M. I., Bakay, R. A., Rezai, A., Marks, W. J. Jr., Moro, E., Vitek, J. L., Weaver, F. M., Gross, R. E., and DeLong, M. R. (2011). Deep brain stimulation for Parkinson disease: an expert consensus and review of key issues. Arch. Neurol. 68, 165-171.

Bronte-Stewart, H., Taira, T., Valldeoriola, F., Merello, M., Marks, W.
J. Jr., Albanese, A., Bressman, S., and Moro, E. (2011). Inclusion and exclusion criteria for DBS in dystonia. Mov. Disord. 26(Suppl. 1), S5-S16.

Collins, K. L., Lehmann, E., and Patil, P. G. (2010). Deep brain stimulation for movement disorders. Neurobiol. Dis. 38, 338-345.

Coubes, P., Roubertie, A., Vayssiere, N., Hemm, S., and Echenne, B. (2000). Treatment of DYT1-generalised dysnal globus pallidus. Lancet 355, 2220-2221.

Detante, O., Vercueil, L., Krack, P., Chabardes, S., Benabid, A. L., and Pollak, P. (2004). Off-period dystonia in Parkinson's disease but not generalized dystonia is improved by high-frequency stimulation of the subthalamic nucleus. Adv. Neurol. 94, 309-314.

Deuschl, G., Schade-Brittinger, C., Krack, P., Volkmann, J., Schäfer, H., Bötzel, K., Daniels, C., Deutschländer, A., Dillmann, U., Eisner, W., Gruber, D., Hamel, W., Herzog, J., Hilker, R., Klebe, S., Kloss, M., Koy, J., Krause, M., Kupsch, A., Lorenz, D., Lorenzl, S., Mehdorn, H. M., Moringlane, J. R., Oertel, W., Pinsker, M. O., Reichmann, H., Reuss, A., Schneider, G. H., Schnitzler, A., Steude, U., Sturm, V., Timmermann, L., Tronnier, V., Trottenberg, T., Wojtecki, L., Wolf, E., Poewe, W., Voges, J., and German Parkinson Study Group. (2006). Neurostimulation section. A randomized trial of deep-brain stimulation for Parkinson's disease. N. Engl. J. Med. 31, 896-908.

Dostrovsky, J. O., and Lozano, A. M. (2002). Mechanisms of deep brain stimulation. Mov. Disord. 17(Suppl. 3), S63-S68.

Fasano, A., Romito, L. M., Daniele, A., Piano, C., Zinno, M., Bentivoglio, A. R., and Albanese, A. (2010). Motor and cognitive outcome in patients with Parkinson's disease 8 years after tonia by stimulation of the inter-

in multiple sclerosis, pain and cluster headache, hypertension, minimally conscious state, obesity, memory impairment, aggressiveness, drug addiction, and other CNS disorders will increase the number of indications for DBS in the future (Lyons, 2011). However, the fact that FDA allowed DBS to be used in dystonia or OCD under an humanitarian device exemption (HDE) application, thereby without the need for a randomized clinical trial of sufficient size to demonstrate statistically significant benefit without undue harm, has spurred impassioned debate on the regulatory and ethical issues linked to the clinical use of DBS (Fins et al., 2011). These issues likely will become even more urgent as the number of indications for DBS treatment will increase.

subthalamic implants. Brain 133 2664-2676.

Fins, J. J., Mayberg, H. S., Nuttin, B., Kubu, C. S., Galert, T., Sturm, V., Stoppenbrink, K., Merkel, R. and Schlaepfer, T. E. (2011). Misuse of the FDA's humanitarian device exemption in deep brain stimulation for obsessive-compulsive disorder Health Aff. (Millwood) 30, 302-311.

Fishman, P. S. (2008). Paradoxical aspects of parkinsonian tremor. Mov. Disord. 23, 168-173.

Follett, K. A., Weaver, F. M., Stern, M., Hur, K., Harris, C. L., Luo, P., Marks, W. J. Jr., Rothlind, J., Sagher, O., Moy, C., Pahwa, R., Burchiel, K., Hogarth, P., Lai, E. C., Duda, J. E., Holloway, K., Samii, A., Horn, S., Bronstein, J. M., Stoner, G., Starr, P. A., Simpson, R., Baltuch, G., De Salles, A., Huang, G. D., Reda, D. J., and CSP 468 Study Group. (2010). Pallidal versus subthalamic deep-brain stimulation for Parkinson's disease. N. Engl. J. Med. 362, 2077-2091.

Gradinaru, V., Mogri, M., Thompson, K. R., Henderson, J. M., and Deisseroth, K. (2009). Optical deconstruction of parkinsonian neural circuitry. Science 324, 354-359.

Hariz, M. I., Blomstedt, P., and Zrinzo, L. (2010). Deep brain stimulation between 1947 and 1987: the untold story. Neurosurg. Focus 29, E1.

Hwynn, N., Hass, C. J., Zeilman, P. Romrell, J., Dai, Y., Wu, S. S., Foote, K. D., Subramony, S. H., Oyama, G., Velez-Lago, F., Fernandez, H. H., Resnick, A. S., Malaty, I. A., and Okun, M. S. (2011). Steady or not following thalamic deep brain stimulation for essential tremor. J. Neurol. 258, 1643-1648.

Katz, M., Kilbane, C., Rosengard, J., Alterman, R. L., and Tagliati, M. (2011). Referring patients for deep brain stimulation: an improving practice. Arch. Neurol. 68, 1027-1032.

Kleiner-Fisman, G., Herzog, J., Fisman, D. N., Tamma, F., Lyons,
K. E., Pahwa, R., Lang, A. E., and Deuschl, G. (2006). Subthalamic nucleus deep brain stimulation: summary and meta-analysis of outcomes. Mov. Disord. 21(Suppl. 14), S290-S304.

Kopell, B. H., Molnar, G. F., and Hiner, B. (2009). "Movement disorders: anatomy and physiology relevant to deep brain stimulation," in Neuromodulation, Vol. 2, eds E. Krames, P. H. Peckham, and A. H. Rezai (London: Elsevier), 529-538.

Kupsch, A., Benecke, R., Müller, J., Trottenberg, T., Schneider, G. H., Poewe, W., Eisner, W., Wolters, A., Müller, J. U., Deuschl, G., Pinsker, M. O., Skogseid, I. M., Roeste, G. K., Vollmer-Haase, J., Brentrup, A., Krause, M., Tronnier, V., Schnitzler, A., Voges, J., Nikkhah, G. Vesper, J., Naumann, M., Volkmann, J., and Deep-Brain Stimulation for Dystonia Study Group. (2006). Pallidal deep-brain stimulation in primary generalized or segmental dystonia. N. Engl. J. Med.355, 1978-1990.

Lulé, D., Heimrath, J., Pinkhardt, E. H., Ludolph, A. C., Uttner, I., and Kassubek, J. (2012). Deep brain stimulation and behavioural changes: is comedication the most important factor? Neurodegener. Dis. 9, 18-24.

Lyons, K. E., Pahwa, R., Comella, C. L., Eisa, M. S., Elble, R. J., Fahn, S., Jankovic, J., Juncos, J. L., Koller, W. C., Ondo, W. G., Sethi, K. D., Stern, M. B., Tanner, C. M., Tintner, R., and Watts, R. L. (2003). Benefits and risks of pharmacological treatments for essential tremor. Drug Saf. 26, 461-481.

Lyons, M. K. (2011). Deep brain stimulation: current and future clinical applications. Mayo Clin. Proc. 86, 662-672.

McIntyre, C. C., and Hahn, P. J. (2010). Network perspectives on the mechanisms of deep brain stimulation. Neurobiol. Dis. 38, 329-337. 
McIntyre, C. C., Savasta, M., Walter, B. L., and Vitek, J. L. (2004). How does deep brain stimulation work? Present understanding and future questions. J. Clin. Neurophysiol. 1, 40-50.

Moro, E., Lozano, A. M., Pollak, P., Agid, Y., Rehncrona, S., Volkmann, J., Kulisevsky, J., Obeso, J. A., Albanese, A., Hariz, M. I., Quinn, N. P., Speelman, J. D., Benabid, A. L., Fraix, V., Mendes, A., Welter, M. L., Houeto, J. L., Cornu, P., Dormont, D., Tornqvist, A. L., Ekberg, R., Schnitzler, A., Timmermann, L., Wojtecki, L., Gironell, A., Rodriguez-Oroz, M. C., Guridi, J., Bentivoglio, A. R., Contarino, M. F., Romito, L., Scerrati, M., Janssens, M., and Lang, A. E. (2010). Long-term results of a multicenter study on subthalamic and pallidal stimulation in Parkinson's disease. Mov. Disord. 25, 578-586.

Pollak, P., Benabid, A. L., Gross, C., Gao, D. M., Laurent, A., Benazzouz, A., Hoffmann, D., Gentil, M., and Perret, J. (1993). Effects of the stimulation of the subthalamic nucleus in Parkinson disease. Rev. Neurol. (Paris) 149, 175-176.

Schrag, A., and Quinn, N. (2000). Dyskinesias and motor fluctuations in Parkinson's disease. A community-based study. Brain 123, 2297-2305.

Schuurman, P. R., Bosch, D. A., Merkus, M. P., and Speelman, J. D. (2008). Long-term follow-up of thalamic stimulation versus thalamotomy for tremor suppression. Mov. Disord. 23, 1146-1153.

Schwalb, J. M., and Hamani, C. (2008). The history and future of deep brain stimulation. Neurotherapeutics 5, 3-13.

Shah, R. S., Chang, S. Y., Min, H. K., Cho, Z. H., Blaha, C. D., and Lee, K. H. (2010). Deep brain stimulation: technology at the cutting edge. J. Clin. Neurol. 6, 167-182.

Skidmore, F. M., Rodriguez, R. L., Fernandez, H. H., Goodman, W. K. Foote, K. D., and Okun, M. S. (2006). Lessons learned in deep brain stimulation for movement and neuropsychiatric disorders. CNS Spectr. 11, 521-536.

Stefani, A., Lozano, A. M., Peppe, A., Stanzione, P., Galati, S., Tropepi, D., Pierantozzi, M., Brusa, L., Scarnati, E., and Mazzone, P. (2007). Bilateral deep brain stimulation of the pedunculopontine and subthalamic nuclei in severe Parkinson's disease. Brain 130, 1596-1607.

Sun, B., Chen, S., Zhan, S., Le, W., and Krahl, S. (2007). Subthalamic nucleus stimulation for primary dystonia and tardive dystonia. Acta Neurochir. Suppl. 97, 207-214.

Vidailhet, M., Vercueil, L., Houeto, J. L., Krystkowiak, P., Benabid, A. L., Cornu, P., Lagrange, C., Tézenas du Montcel, S., Dormont, D., Grand, S., Blond, S., Detante, O., Pillon, B., Ardouin, C., Agid, Y., Destée, A., Pollak, P., and French Stimulation du Pallidum Interne dans la Dystonie
(SPIDY) Study Group. (2005). Bilateral deep-brain stimulation of the globus pallidus in primary generalized dystonia. N. Engl. J. Med. 352, 459-467.

Volkmann, J., Daniels, C., and Witt, K. (2010). Neuropsychiatric effects of subthalamic neurostimulation in Parkinson disease. Nat. Rev. Neurol. 6, 487-498.

Weaver, F. M., Follett, K., Stern, M., Hur K., Harris, C., Marks, W. J. Jr., Rothlind, J., Sagher, O., Reda, D., Moy, C. S., Pahwa, R., Burchiel, K., Hogarth, P., Lai, E. C., Duda, J. E., Holloway, K., Samii, A., Horn, S., Bronstein, J., Stoner, G., Heemskerk, J. Huang, G. D., and CSP 468 Study Group. (2009). Bilateral deep brain stimulation vs best medical therapy for patients with advanced Parkinson disease: a randomized controlled trial. JAMA 301, 63-73.

Welter, M. L., Grabli, D., and Vidailhet, M. (2010). Deep brain stimulation for hyperkinetics disorders: dystonia, tardive dyskinesia, and tics. Curr. Opin. Neurol. 23, 420-425.

Wichmann, T., and Delong, M. R. (2006). Deep brain stimulation for neurologic and neuropsychiatric disorders. Neuron 52, 197-204.

Wilcox, R. A., Cole, M. H., Wong, D., Coyne, T., Silburn, P., and Kerr, G. (2011). Pedunculopontine nucleus deep brain stimulation produces sustained improvement in primary progressive freezing of gait. J. Neurol. Neurosurg. Psychiatr. 82, 1256-1259.
Williams, A., Gill, S., Varma, T., Jenkinson, C., Quinn, N., Mitchell, R., Scott, R., Ives, N., Rick, C., Daniels, J., Patel, S., Wheatley, K., and PD SURG Collaborative Group. (2010). Deep brain stimulation plus best medical therapy versus best medical therapy alone for advanced Parkinson's disease (PD SURG trial): a randomised, open-label trial. Lancet Neurol. 9, 581-591.

Wirdefeldt, K., Adami, H. O., Cole, P., Trichopoulos, D., and Mandel, J. (2011). Epidemiology and etiology of Parkinson's disease: a review of the evidence. Eur. J. Epidemiol. 26(Suppl. 1), S1-S58.

Conflict of Interest Statement: The authors declare that the research was conducted in the absence of any commercial or financial relationships that could be construed as a potential conflict of interest.

Received: 05 November 2011; accepted: 09 January 2012; published online: 25 January 2012.

Citation: Pizzolato $G$ and Mandat $T$ (2012) Deep brain stimulation for movement disorders. Front. Integr. Neurosci. 6:2. doi: 10.3389/fnint.2012.00002

Copyright (c) 2012 Pizzolato and Mandat. This is an open-access article distributed under the terms of the Creative Commons Attribution Non Commercial License, which permits noncommercial use, distribution, and reproduction in other forums, provided the original authors and source are credited. 